\title{
Nathan Miczo* \\ The ethics of news media reporting on coronavirus humor
}

\author{
https://doi.org/10.1515/humor-2021-0011 \\ Received August 28, 2020; accepted February 28, 2021; \\ published online April 2, 2021
}

\begin{abstract}
This essay explores the news media's portrayal of humor during the early phase of COVID-19-related lockdowns. Examining a collection of online news articles reveals the media tended to frame the issue as an ethical one (e.g., "is it okay to laugh at the coronavirus?"). After reviewing work on humor ethics, a qualitative content analysis of 20 news media articles is presented. Three issues from the news stories are identified, allowing comparison of the media's claims against the ethical principles articulated. The essay concludes with a consideration of how news media's coverage of humor fits within a broader pandemic narrative.
\end{abstract}

Keywords: coping humor; coronavirus humor; humor ethics

\section{Introduction}

In late December 2019, reports emanated from Wuhan, China, of a novel coronavirus, subsequently named 2019-nCOV and giving rise to COVID-19 (i.e., Coronavirus Disease 2019). By January 8, 2020, 59 cases were suspected, with two deaths reported within the following week. In the United States, the first case was reported on January 20th, and, by the end of the month, 9,976 cases had been reported across 21 countries (Holshue et al. 2020). Winter gave way to spring, with the world facing a global pandemic. As containment efforts failed, steps were taken to mitigate COVID-19's impact. In the U.S., Washington State declared a state of emergency on February 29th, with additional states following suit by early March. By mid-to late-March, most U.S. states had gone beyond mitigation to lockdown (Wikipedia 2020). Under these shelter-in-place orders, citizens were urged to remain at home except for essential travel, to wear masks when entering public spaces, to wash and sanitize hands frequently, and to practice social distancing (maintaining at least six feet of space from one another).

*Corresponding author: Nathan Miczo, Western Illinois University, Macomb, USA, E-mail:n-miczo@wiu.edu 
The word "unprecedented" became ubiquitous, repeatedly used to describe many people's experiences during the initial lockdown period and subsequent transition to conducting life from home, largely via computer or other electronic devices. One communicative behavior that quickly emerged as a response to the circumstances was humor, spread largely through social media (Amici 2020; Bischetti et al. 2020). This was, perhaps, not unexpected, as past crises and disasters have also given rise to outbreaks of humor (Kuipers 2005; Smyth 1986). In fact, it has been argued that disaster jokes as a genre are coeval with the advent of television (Oring 1992), a way of rebelling against the relentless news coverage typically given to high profile tragedies. Davies (2003) predicted that the rise of the Internet would result in the globalization of disaster jokes, allowing the "official pieties" (p. 30) of broadcasters to be evaded.

Broadcast media, in this case news media, however, are not so easily evaded, as they themselves devoted attention to the pandemic humor circulating via social media. Several factors may help to explain this coverage. For one thing, humor transmission via electronic format means that the jokes and memes can be stored and retrieved for subsequent reporting. Second, the rise of humorous news programs has blurred the distinction between news genres, promoting an eagerness among traditional news outlets to appear culturally relevant (Williams and Carpini 2009). Finally, the growth of humor studies has provided a storehouse of ideas and authorities that can be tapped to provide journalistic insight and arguments for humor's place in the current pandemic.

This essay explores the way the news media portrayed humor's role during the early phase of the COVID-19-related lockdown. Upon examining a collection of online news articles, it became evident that the news media was doing more than just reporting on the circulation of humor via social media. Rather, the media tended to frame the issue as an ethical one (e.g., "is it okay to laugh at the coronavirus?"), and then proceeded to answer affirmatively. In order to analyze this phenomenon, it is first necessary to review work on humor ethics. Next, a qualitative content analysis is presented, which allows for comparison of the media's claims against the ethical principles articulated. The essay concludes with a consideration of news media's coverage of humor as it fits within a broader pandemic narrative (Gerlach 2016).

\section{Ethics of humor}

Much of the humor ethics literature focuses upon sexist and racist jokes. On the face of it, these ethical approaches should shed little light on pandemic humor, other than obvious platitudes against targeting marginalized groups. Insofar as 
racist/sexist jokes are still jokes, however, something may be gleaned from their consideration. De Sousa (1987) provides a much-criticized starting position, arguing that every joke rests upon certain premises, and those premises involve beliefs and attitudes. To understand a joke means one must understand those attitudes. However, since attitudes cannot be held hypothetically, to find a joke funny, to laugh at it, means one endorses the expressed attitudes. If a joke is racist, laughing at the joke implies endorsing its racist premises, and endorsing those premises means that you are, in fact, a racist.

Criticism of de Sousa (1987) focuses on the claim that laughter implies attitudinal endorsement. Benatar (1999) distinguished between racial/sexual humor (which turns upon stereotypes) and racist/sexist humor (which is intended to harm members of the stereotyped group), but Smuts (2010) points out that determining all of a joke's presuppositions can be difficult and open to debate. Conceding that laughter, or lack thereof, need not imply endorsement of any particular aspect of joke content, then raises the question of ethical harm. If jokes are "mere amusement," where is the harm? Benatar (1999) argued that racist/sexist jokes are wrong because they harm the esteem of the targeted other(s). Such jokes lower the way those portrayed are regarded by others, and since we generally prefer to be regarded well rather than poorly, it harms their interests. Smuts (2010) contended that laughter directed at others causes harm by leaving "emotional scars." Being laughed at is therefore harmful, a view supported by research on gelotophobia (Ruch et al. 2014; Titze 2009). Since our sense of humor often gives rise to our laughter (to what we find funny), we can be held responsible for being the kind of person who possesses a sense of humor that produces harmful laughter directed at others. Smuts' (2010) position is consequentialist; humor is wrong when it has harmful consequences.

Focusing exclusively on de Sousa's (1987) attitudinal endorsement thesis (as Smuts refers to it) overlooks the basis of his agent-centered approach. De Sousa (1987) argued that certain forms of humor are ethically wrong because they harm the joke-teller. That is, to participate in joking is to engage in the cognitive and affective elements that are part of the joke's attitude. In the case of racist/sexist jokes, one engages the dialectic of identification/alienation. The possibility of identifying with another is the basis of the right to laugh at that other. When we laugh together, we signal to ourselves and others a similarity that is a basis for identification. A racist joke, directed at a differently-grouped other (rather than a similarly-grouped other) involves a laughing at relation, expresses alienation, thereby obviating the possibility of identification. Insofar as such jokes rely on stereotypes, the alienation is based on an overly simplified view that denies, or overlooks, the complex reality of living persons. The harm to joke-tellers is 
two-fold: through alienation they foreclose the possibilities of relating, and by resting content with simplification, they deceive themselves.

A similar conclusion is reached by Morreall (2009) in his consideration of humor ethics. At the heart of Morreall's argument is the idea that humor entails a disengagement from practical activities. When engaging in humor, we become less concerned with goal pursuit and seeking personal advantage. Rather, like aesthetic experiences in general, we are in the moment, oriented toward the enjoyment of the humorous mode as an end in itself. The idea of disengagement thereby furnishes a criterion for considering the potential harms of humor and Morreall mentions three specific issues. First, humor may foster irresponsibility. When we treat an issue with humor, we trivialize it and construct it as something not requiring our sustained attention and devotion. Second, humor can block compassion. As he argues, humor can be harmful "by displacing action, and by insulting those who are suffering, thus increasing their suffering” (p. 103). Third, humor can promote prejudice. However, contra de Sousa's (1987) position, Morreall contends that joke-tellers and audiences are unlikely to believe (much less endorse) the exaggerated characteristics in joking stereotypes; nevertheless, promulgating such images and ideas can make people indifferent to the truth behind the stereotypes and to the possibility of causing harm. Morreall collectively sums up these possibilities with the following principle: "Do not promote a lack of concern for something about which people should be concerned” (p. 110).

Similarly moving beyond the reliance on sexist/racist humor, Peifer's (2012) concern is political humor, defined as humor that circulates in the public sphere. Such humor reflects current events, and insofar as it is part of the public discourse surrounding those events, it can be held to certain standards of public discourse. To determine those duties and responsibilities, he draws upon social responsibility theory (SRT; Christians and Nordenstreng 2004). SRT, as articulated by Christians and Nordenstreng, represents an attempt to provide a broad, philosophical foundation for journalists' responsibilities to the public. They articulated a set of ethical principles, or metanorms, that Peifer believes are applicable to humor in the public sphere: dignity, non-maleficence, and truthfulness. Applying these principles is not straightforward, due to humor's non-bona-fide nature, but they can serve as guides for evaluating humor's appropriateness.

The first principle, dignity, has to do with maintaining the respectfulness and sacredness of individuals, as well as the groups of which they are parts. According to Peifer (2012), the issue is how to respect dignity while poking fun at, or mocking, people in the public sphere. He suggests that "people can benefit by taking themselves less seriously" (p. 271). The notion of poking fun at oneself can then be connected with the idea of creating humor from one's own experience. For some individuals, original humor, as opposed to joke-telling, is the essence of being 
funny (Kuipers 2006). However, those adept at telling jokes often emphasize the individuating characteristics of performance (Kuipers) or the use of jokes as commentary (Oring 2003). Both ways of being funny are therefore relevant to humorous dignity.

Non-maleficence involves "no harm to the innocent" (Christians and Nordenstreng 2004, p. 23). Peifer (2012) configures the principle to being aware of humor's potential for hurtfulness, acknowledging that humor can damage reputations and create hurt feelings. This principle could be further expanded by referencing prejudiced norm theory (Ford and Ferguson 2004), which proposes that humor can act as a releaser of pre-existing prejudices or biases, allowing people to feel more comfortable to express or act upon beliefs they might otherwise suppress. Rather than just a matter of hurt feelings, then, maleficent humor can lead to discriminatory behavior (Ford et al. 2015; Katz and Wing-Paul 2020).

Truthfulness, the final principle, is also the most complex. According to Christians (2011), truth involves authentic disclosure rather than just veridicality with an objective reality. It "unveils the inner character of a series of events" (p. 197), and focuses on interpretive sufficiency. Peifer (2012) adheres closely to this articulation, urging humorists to "represent the essence of truth in a given situation” (p. 273, emphasis in original). Humor, then, can be a means for drawing attention to problematic issues (Chattoo and Feldman 2020), at times, giving voice to, and therefore revealing, what is unspoken.

The purpose of these principles is not to stifle humor's capacity to offer commentary in the public sphere, but to articulate the boundaries within which humor can do so efficaciously. That is, humor can play a legitimate role in drawing attention to issues and engaging the emotions of citizens in debate (Benacka 2017), thereby furthering and contributing to public communication; but humor that transgresses these bounds runs the risk of undermining the public sphere by spreading misinformation and alienating groups whose interests are part of the public.

These three principles articulate well with the three perspectives discussed earlier. Dignity aligns with Benatar's (1999) notion that disparagement humor undermines the esteem and regard of target groups. Non-maleficence accords well with Smuts' (2010) view that laughter can cause emotional harm to targets. Truthfulness is virtually identical with de Sousa's (1987) argument that humor can lead to a flawed assessment of reality, as well as Morreall's (2009) contention that humor can make one indifferent to truths. Collectively, these three principles illustrate humor's ethical dimension. They raise the possibility for debate about humor and how it is used. Even in the time of coronavirus, humor should be truthful, while respecting dignity and avoiding non-maleficence. News media can similarly be held to the same standards in its framing of humor. 


\section{Coronavirus humor and the news media}

News media are one of the institutions of modern societies providing information about events, including health-related events such as pandemics. They are a key mediator between the state and civil society, shaping public understandings and influencing individual actions (Davis 2017). They also continue to be a primary source of information for the public. Chew and Eysenbach (2010) examined Twitter posts during the H1N1 outbreak and found that posting activity coincided with news reporting of the disease. With regard to COVID-19, research by Krawczyk et al. (2020) suggests a similar pattern, with public attention following the news media's reporting of the pandemic rather than tracking actual disease progression. At the time, Americans appeared to hold generally favorable opinions of the news media's coverage of the virus, with 59\% agreeing that the media was giving them the information they needed (Pew Research Center 2020). Though coverage was heterogeneous, rather than exclusively negative, Krawczyk et al. found that a cluster of the terms death, fear, and crisis, accounted for a non-trivial percentage of the negative coverage. They speculated that the sheer volume of reporting may have led to information overload.

Briggs and Nichter (2009) define biocommunicability as the production, circulation, and reception of biomedical knowledge. Examining the information context of H1N1, they describe the Goldlilocks principle, a balancing act "between taking disruptive precautions or irresponsibly doing nothing” (p. 192). A similar pattern was evident early on with the Coronavirus (Gozzi et al. 2020), until it became clear that the world was not going to dodge this viral bullet. With the announcement of a global pandemic by WHO on March 11, 2020, and the institution of lockdown orders in many countries, the balance tipped in favor of "disruptive precautions" (i.e., lockdowns and stay-at-home orders). The media was then well situated to shape unfolding understandings of the pandemic. The situation had many of the features which, according to Kuipers (2005: 70), prove ripe for disaster jokes; it was "highly covered by the media, much talked about, tragic but undeniably sensational.” On March 4th, Prince William was recorded at a public event joking about Coronavirus and asking "Is it being hyped up, do you think, by the media?" (Gajanan 2020). The real deluge of humor, of course, came in the following weeks and much of it circulated via social media.

This project began with a preliminary Google search, conducted on May 20, 2020, using keywords "COVID-19 humor" and "Coronavirus humor." The number of news media articles about the pandemic caught my eye, and the questions raised about humor's appropriateness suggested an analysis from the standpoint of humor ethics. The analysis, then, is not concerned with any particular example or collection of humor. Rather, my concern here is with what the news media said 
about humor, and how well that discourse adhered to the principles articulated earlier. There is also no claim to representativeness in either the quantitativestatistical sense nor the more qualitative sense of broad cultural representation. Follow-up Google searches were conducted on May 25, 2020 and June 11, 2020. Inclusion criteria were that the articles were published in English, available online, and that the source was an online newspaper, newsletter, or news magazine about Coronavirus humor in general (rather than focused on specific topics, such as humor about toilet paper hoarding). Most of the 15 articles found at that time were from the U.S., with a few additional countries also represented. In January 2021, a final search was conducted, looking for articles from the same time period that might have been overlooked earlier. Five new articles were found; however, no new ideas or themes were evident, suggesting a saturation point had been reached.

The articles were published between March and early June 2020 (see Table 1). ${ }^{1}$ Thus, the coverage of humor parallels Lemish and Elias's (2020) findings that humor in Israel was prominent between March and May, before attention turned to

Table 1: News media articles on COVID-19 humor used in the analysis.

\begin{tabular}{lll}
\hline Source & Date & Author \\
\hline Wired & March 5, 2020 & Emma Gray Ellis \\
Vox & March 6, 2020 & Danna Takriti \\
The Conversation & March 15, 2020 & Herman Wasserman \\
DailyMail & March 16, 2020 & Joseph Laws \\
Chicago Reader & March 19, 2020 & Brianna Wellen \\
Reuters & March 24, 2020 & Barbara Goldberg \\
CNET & March 26, 2020 & Abrar Al-Heeti \\
Denver Post & March 26, 2020 & William J. Kole \\
The Atlantic & April 3, 2020 & Tom McTague \\
USA Today & April 3, 2020 & Erin Jensen \\
Univ. of Miami & April 20, 2020 & Michael R. Malone \\
NY Times & April 22, 2020 & Alex Williams \\
The Columbia Chronicle & April 23, 2020 & Lauren Leazenby \\
LA Times & April 30, 2020 & Chris Erskine \\
Psychology Today & May 1 2020 & Jamie D. Aten \\
Verywellmind & May 11, 2020 & Sherri Gordon \\
The Conversation & May 5, 2020 & Gil Greengross \\
Jewish Exponent & June 3, 2020 & Eric Schucht \\
ScienceNordic & June 5, 2020 & Mette Møller \\
North Jersey & June 17, 2020 & Jim Beckerman \\
\hline
\end{tabular}

1 See Aten (2020), Beckerman (2020), Davies (2002), Gordon (2020), Hileman (2020), Laws (2020), Leazenby (2020), Malone (2020), Møller (2020), and Schucht (2020). 
other topics. A similar pattern also occurred during the H1N1 pandemic, where humorous tweets surged during the initial wave of media coverage before dropping off sharply (Chew and Eysenbach 2020). A qualitative analysis was undertaken. Following Riessman (1993), I began by examining the structure of the articles. From there, I turned to identifying themes, using Fraser's (2004) narrative approach as a guide. The emerging set of themes was compared against the ethical criteria of Peiffer (2012).

\section{Coronavirus humor in the news media}

In terms of structure, there were notable commonalities across the articles. First, headlines tended to frame COVID-19 humor in terms of appropriateness. While some headlines simply noted the presence of humor on social media, others framed the issue as a question ("Jokes in the time of coronavirus: How soon is "too soon" when you're living through it?” Wellen 2020) or affirmatively addressed the presumed question ("Yes, make coronavirus jokes," McTague 2020). Second, virtually all articles began with examples of humor. Kole (2020) opened his article mentioning Neil Diamond's posting a revised version of "Sweet Caroline" with lyrics "Hands ... washing hands." Jensen (2020) quoted a joke from Norm MacDonald, "Remember the good old days, when washing your hands didn't take 3 h?” Additionally, articles noted that humor was circulating via social media, with many embedding examples of memes, or clickable links to TikTok or YouTube videos. News media were thereby participating in circulating the very humor they were reporting on.

Third, some articles described how humor had also been created in the wake of past disasters and tragedies (e.g., the Holocaust, the world wars, 9/11). For example, Williams (2020) cited WWI journalist Philip Gibbs' reports on how soldiers in the trenches often unearthed comrades' body parts. The reference to a "bit of Bill" in the trenches became a grim source of joking: "Generals chuckled over it, chaplains treasured it.” Nevertheless, this sort of gallows humor helped men deal with the starkness of their situations. Some authors did qualify comparisons between COVID-19 and past disasters by mentioning the slower pace of the virus's spread, rather than the suddenness of some past events (e.g., JFK assassination, 9/11 attacks). Nevertheless, this feature is structural because it was invariably used to frame the argument that individuals use humor to cope during times of stress and crisis.

Fourth, articles tended to reference three kinds of experts. One type was comedians. Wellen's (2020) article, for example, was almost entirely quotes from comedians about their perceptions of humor in the present circumstances. Kole (2020) quotes comedian Erica Rhodes, "Laughter is a symbol of hope, and it becomes one of our greatest needs of life, right up there with toilet paper.” A second 
type of expert included psychologists, psychiatrists, and stress managers. The majority of these experts discussed humor as a coping response (to be detailed below). The final types of expert prominently featured were humor researchers. Peter McGraw and Caleb Warren were cited three times, Robert Provine's work on laughter was cited twice, Scott Weems, Paul Lewis, and John C. Meyer were each mentioned once. One article was authored by Gil Greengross. Of course, some of these humor researchers are also psychologists. The credibility of experts establishes the authority of news media reporting. The selection of experts thus works as a framing device insofar as it shapes interpretations: in this case, humor is framed as an individual response to stress, a position backed up by experts who study individuals. By contrast, researchers who have studied disaster humor from a sociological or cultural perspective (e.g., Oring, Davies, Kuipers) were not quoted or cited.

In terms of structural features, then, the articles tended to frame humor as an individual response to the stressful circumstances surrounding the COVID-19 pandemic. As noted earlier, many articles implicitly or explicitly suggested that audiences might feel uncomfortable about the widespread appearance of humor, might be guilty perhaps, wondering if they should be laughing at a situation with so much potential for tragedy. By virtue of raising the issue in this way, the articles were making claims about better and worse courses of action. Insofar as this is an entré point for ethical debate, these claims can be evaluated in light of Peiffer's (2012) three ethical principles from Social Responsibility Theory (Christians and Nordenstreng 2004). The following analysis uses those ethical principles to examine the content of news media stories about COVID-19 humor.

\section{Social responsibility theory}

\subsection{Principle one: dignity}

Dignity has to do with respecting the sacredness of individuals and their unique experiences. Translated into the terms of humor, this is equivalent to suggesting that people create humor from their own standpoint. Comedian Cameron Esposito advised "talking about your own life and your relationship to the topic" (Jensen 2020). Williams (2020) wrote "we are all our own best source of humor, racked with anxiety as we sit cloistered at home, surrounded by either too few people or too many." Kole (2020) quotes comedian Erica Rhodes, "The best material comes from a place that's very truthful and somewhat dark." Singer Chris Mann, who did "My Corona" and created a parody of Adele's "Hello (From the Inside)" revealed "I don't know that I've ever been this honest as a creator" (Erskine 2020). It would seem, overall, that the news media fared well by this standard. 
While these quotes illustrate that COVID-19 humor should be created from one's own experiences, the articles principally focused upon receiving and forwarding content to others. McTague (2020) began his article by describing reception of a video in a family WhatsApp group; Wellen (2020) talked about surrounding herself with comedians on every social media platform. Erskine (2020) pointed out Americans were "laughing, mocking and sharing across social media platforms that are bursting with content." Thus, though the advice adhered to the principle of humorous dignity, the broader point touched upon the circulation of humor, where it can be assumed that far more people were forwarding humor not of their own creation. Research by Amici (2020) in an Italian sample suggests that individuals were motivated to republish material they found amusing, even though they did not always search for it. Nevertheless, there is consistency if this is interpreted as claiming that humor should, at the very least, resonate with one's experiences.

\subsection{Principle two: non-maleficence}

Non-maleficence is about the line between poking fun at someone in the public sphere and doing them harm A couple articles mentioned the possibility of misinformation being spread via humor, thereby causing harm (Al-Heeti 2020; Wasserman 2020). By far, however, the articles were virtually unanimous is asserting that humor should not target the weak, the sick, and the disempowered. Erskine (2020) quoted professor of digital social media Karen North, "No one is making jokes about the disease. People are making jokes about our hugely altered lifestyles.” Greengross (2020) wrote, "Obviously, we do not laugh at the tragedy itself, the victims of the virus or the people who are suffering from it. But we can take aim at the seemingly absurd situation we are all in.” Kole (2020): No one wants to poke fun at medical misery or death. Quarantining and social distancing, though, are fair game, and self-deprecating humor is almost always safe.” A few articles also included warnings that humor could turn dark if the situation became grimmer. Overall, however, the news media appear to fare well against this standard.

\subsection{Principle three: truthfulness}

Though humor may traffic in the non-bona-fide world (Raskin 1985), with its own rules and logic (Mulkay 1988), the ethical principle of truthfulness concerns the veracity with which humor alludes to, or captures, the essence of a situation. In this case, that essence involves the framing of COVID-19 humor in terms of motivations. 
In other words, why were people posting and circulating jokes and memes? Three subcategories were identified regarding the functions served by humor during the early stages of media coverage and lockdown orders.

\subsubsection{Humor is good for connection, for helping us feel a sense of togetherness}

Erskine (2020) quotes professor Karen North: "Right now, in an unprecedented way, we all have a shared worldview." Wasserman (2020) writes "joking about the coronavirus may be a way for people to say 'it is all very absurd, but we're in this together." Wellen (2020) quotes comedian Katie Baker, “As devastating as this has been for humankind on a global scale, I feel like in this horrifying moment, we're almost unified as a species.” As Amici (2020) found, many people reported sending humor to amuse others. Williams (2020) did suggest a generational difference in this regard, with Baby Boomers and Gen-Xers seeming to prefer the "we're all in this together" type of humor while Gen-Z slanted toward darker humor, reflecting their belief that little would be left for them. In the main, however, articles emphasized humor's power to unify and create feelings of togetherness.

However, emerging evidence reveals the limits of this idea. The same Pew report (2020) that suggested generally favorable views of U.S. news media also showed glaring differences between Democrats and Republicans. Jaeger and Blaabaek (2020) found that lockdown amplified inequalities in family's educational and learning opportunities. In Israel, Kristal and Yaish (2020) found that the virus-fueled economic downturn exacerbated gender inequalities. Research in Britain (Hu 2020), France (Recchi et al. 2020) and China (Qian and Fan 2020) reports that certain groups have experienced more economic hardship than others in the wake of lockdowns. With respect to humor preferences, Bischetti et al. (2020) found that those who were more at-risk and those closer to the Italian epicenter found COVID-19 humor more aversive and less funny. Collectively, these findings suggest we were never all in this together. Rather than question the assumption of global unity, the news media reinforced it.

\subsubsection{Laughter is good medicine}

This idea was mentioned by several articles, though only a few of them provided any elaboration. The following were perhaps the most detailed:

Goldberg: Mental health professionals say humor is a balm for soothing nerves, not just by tickling funny bones but also by decreasing stress hormones. Clinical evidence shows high levels of stress can weaken immune systems. 
Gordon: Laughter also increases the number of antibody-producing cells we have working in our bodies. And, it enhances our T-cells, which are at the core of adaptive immunity and help tailor our immune response. All of this equates to a stronger immune system.

Williams: There is a reason laughter has long been considered the best medicine. It releases bursts of dopamine, a hormone and neurotransmitter that signals pleasure and reward, and studies have indicated that it also can improve blood flow, immune response, pain tolerance and might even shorten hospital stays, said Scott Weems, a cognitive neuroscientist.

Jensen: McGraw says while there is some "mild" physical benefit to laughing, it's the positive emotions that humor triggers that do us good because they're "incredibly important for our health and well-being."

Though the idea that laughter is the "best medicine" has thoroughly soaked the popular consciousness, the weight of the empirical evidence suggests very limited effects upon the body, both physically and physiologically. As Papousek (2018: 316) argued, the benefits of laughter "correspond to mild, mostly sympathetic nervous system driven activation: transient increase of heart rate and blood pressure, transient rise of stress hormones, minor changes of certain immune parameters and other effects related to emotional arousal." This conclusion is echoed by Martin $(2001,2008)$ who concluded that laughter (or positive emotion more generally) can temporarily elevate pain thresholds, but beyond that the research is contradictory and plagued by methodological shortcomings. Overall, the good feelings generated by laughter are primarily a means of distracting one from negative affect, and do not produce long-term medicinal effects. In situations where distraction is helpful, laughter is warranted, perhaps even recommended.

\subsubsection{Humor is a good coping mechanism}

This idea was a dominant frame in the articles. Table 2 presents a sampling of how it was presented. Implicitly or explicitly, humor and laugher were portrayed as good for defusing fear and anxiety, for helping us re-establish a sense of psychological control and a sense of social connection. On the face of it, there is evidence for humor's beneficial effects. Several studies have found that positive forms of humor correlate positively with subjective well-being (Edwards and Martin 2010; Ford et al. 2016). Papousek (2018) argued that a "cheerful positive affect disposition" is valuable in the face of adversity. Such a disposition lends itself to the active creation of humor mainly focused on oneself and one's circumstances. McGhee (2010) claims something similar, stating that positive humor is one means among many for dealing with stress and other negative emotions. Martin (2001, 2008), too, suggests that the mental health benefits of humor flow from its long-term effects as an emotion regulator. Thus, finding amusement in the 
Table 2: News media articles descriptions of coping benefits.

Goldberg: "It's a really powerful way to manage the unmanageable. Just to make fun of it and to gain control by laughing at it. That's a really powerful psychological move we can make," Truman said.

Greengross: So, while humour may not get us out of this awful crisis, it can help us deal with it. We cannot change the reality of the disease or the economic impact, but we can try and change how we feel about it.

Kole: Laughter can be the best medicine, they argue, so long as it's within the bounds of good taste. And in a crisis, it can be a powerful coping mechanism.

Moller: By joking about coronavirus, we therefore break through a little of the seriousness of the situation and thus ease some of the nervousness that might otherwise stick to us and nag away somewhere inside - consciously or unconsciously.

McTague: We laugh, then, to take back control and to connect-two things we have lost in our fight against the coronavirus. Not only are we unable to stop the tidal wave of infection washing over us, but we are being forced to endure this reality alone in our own home. Powerless and isolated, we're finding that the joke is now our most reliable shield-and our warmest comfort blanket.

Jensen: Maybe most importantly, laughter can help decrease fear.

Wasserman: Humour in this context is a way of showing resilience and agency.

incongruities of one's life, as a habitual response pattern should serve one well in times of trouble and adversity.

Just because humor can be beneficial does not mean that it cannot also be harmful. To explore this requires a further consideration of what it means to cope. Coping involves the attitudes people adopt and the behaviors they engage in when faced with situations and circumstances that exceed their everyday expectations and experiences (Aldwin 1994; Lazarus and Folkman 1984). In other words, people cope with stressful circumstances. Two distinctions within the coping literature are particularly relevant. The first is the difference between emotion- and problemfocused coping. Emotion-coping concerns the relevance of an event to one's wellbeing, while problem-focused coping involves attempts to ameliorate the situation. The second involves approach and avoidance coping strategies (Taylor and Stanton 2007). Approach coping, in one way or another, emphasizes confronting the problem or dealing with those aspects of it that are amenable to one's control. Supporting evidence is not entirely consistent but suggests links with improved physical and psychological outcomes (i.e., adaptive responses). Avoidance coping involves attempts to keep oneself from thinking about the source of stress, perhaps through distraction, minimization, wishful thinking, or consumption of mindaltering substances (e.g., drugs, alcohol). These responses can be helpful when the stressor is short-term or uncontrollable, but, over time, they can make things worse by heightening intrusive negative thoughts and emotions or by dissuading 
adoption of more effective actions. Coping in this manner is linked to poorer physical and psychological outcomes (i.e., maladaptive responses).

These distinctions should not be read as simple dichotomous or independent processes. Rather, they combine in interactive ways and change as a stressful situation unfolds. In any traumatic or stressful circumstance, the presence of negative emotion must be addressed (and therefore is always part of the coping process), but responses such as distraction or alcohol consumption may do little to alter the source of stress and may prevent one from perceiving or developing opportunities to confront the manageable or changeable aspects of the situation. On the other hand, changing one's circumstances, changing one's perceptions, or seeking social support can all be ways of dealing with the problem that foster a perception of manageability. A problem recast as manageable should lessen its relevance to well-being, thereby resulting in reduced levels of negative affect and distress.

Abril et al. (2017) argued that humor can function as a form of message rejection distinct from other reactions. They argue that humor "defuses and depressurizes" fears and that this response is unique because it doesn't deny the threat, it engages rather than avoids, and it doesn't necessarily attempt to restore a threatened freedom. One can quibble with these claims, given that, insofar as humor constructs events as "not serious" or benign, it can be a means of avoiding the implications of events, minimizing their seriousness, or derogating message sources, implicitly if not explicitly. The authors are correct, however, that humor has been overlooked as a message rejection strategy in its own right. Examining naturally occurring twitter responses to the government's TIPS anti-smoking media campaign, they found that, though the overall level of avoidant tweets were low, $86.3 \%$ of those tweets were humorous, followed by reactance $(4.8 \%)$, defensive avoidance (4.5\%), and then denial (2.9\%) (i.e., other kinds of avoidant responses). In a social media environment where users were free to respond as they saw fit, the humorous remarks predominating indicated message rejection.

This finding is further supported by Neben (2015), who argued that, in the face of threat, people may be motivated to actually seek out information, but then fail to fully absorb it or to act upon it. During the initial lockdown period, people may have been circulating humor to get a laugh, to amuse themselves or others, and as a means of distraction. The news media articles provide some evidence of this. Erskine (2020) quotes an actress/writer who told him, "I love a good laugh to distract me," as well as a writer-comedian, who said, "It would appear that people need an escape.” Al-Heeti (2020) quotes a 26-year old publicist, "It's a little bit of reprieve from having to feel constantly scared or anxious or worried about other people. It doesn't remove those feelings. It just distracts me from them for a minute, which is nice." As coping efforts, these activities may work in the short-term for 
fulfilling a motive to seek information, or alleviating negative affect, but they do little to prepare people for long-term solutions. Further, these responses have, traditionally, been labeled maladaptive. It could be argued, then, that the news media failed to link the desire for distraction with the possibility of avoidantemotion-focused coping, thereby presenting a somewhat simplified model whereby humor is presented as "good for coping."

\section{Humor and the pandemic narrative}

If the analysis presented above has merit, then the news media presented a somewhat distorted version of the pandemic situation. This story of people circulating humor via global networks to help themselves and others cope is not false, but perhaps, necessarily partial. But given the unusually high level of media coverage to humor during this pandemic, the question must be raised as to whether or not this partial presentation was somewhat made to fit an existing frame. In other words, did prior media coverage of pandemics, perhaps, contribute frames that the news media could draw upon, knowingly or not. The outbreak narrative suggests one starting point. Wald (2008) described an outbreak narrative as a story with three parts: a biological-viral threat is identified, global networks facilitate its transmission, while the coordinated efforts of experts successfully contain it. Over the last several years, as recurrent threats have surfaced (e.g., SARS, H1N1, Ebola, Zika, H1N5), the biocommunication necessary to manage these threats means that Goldilocks is never able to actually get to sleep. The outbreak narrative has, accordingly, been recast as a pandemic narrative (Gerlach 2016; Greenberg et al. 2019; Mitchell and Hamilton 2018). In this narrative, the threat is omnipresent, potentially emerging “over there” (e.g., Ebola in Africa) but also sometimes bursting forth internally (e.g., measles outbreaks in Disneyland), requiring constant vigilance. Global networks are now more tightly woven than ever, meaning that a virus could spread before knowledge of it becomes official, with the threat outpacing knowledge production. This situation can also be seen in early reports on the possible course that COVID-19 would take (Kupferschmidt and Cohen 2020). In the pandemic narrative, there is no successful containment; citizens can only cope with the threats and learn to manage their uncertainty and anxiety.

On the one hand, the idea that humor is good for something, especially medical somethings (e.g., the Norman Cousins phenomenon), has permeated the popular consciousness. On the other hand, it is interesting to note how news reporting on COVID-19 humor fits the pandemic narrative. In this case, however, the viral threat cannot be easily separated from the social disruption caused by 
lockdown orders. Global networks, in this case social media, were critical in facilitating the circulation of humor among dispersed audiences, who may not have been medical experts, but who were surely capable of creating humor from out of their own experiences. After all, this is what people have always done when the chips were down and the day looked dark: they were resilient and they triumphed and humor was right there as a handmaiden. In line with the narrative, pandemic humor acted as a defense, a "mental armor," people used to cope with the threats and restrictions posed by COVID-19.

How well does this narrative hold up to ethical scrutiny? As is often the case with ethical issues, it fares well in some ways and leaves room for improvement in others. The principles of dignity and non-maleficence were well represented in the news media articles. The notion that people should stay away from making humor about the sick, and the vulnerable, was articulated and reinforced in virtually all the articles. Similarly, individuals were presented with the notion that they should create humor from out of their own lockdown experiences. When it comes to truthfulness, the situation was more complicated, or rather, somewhat more simplified.

Humor may create feelings of togetherness, but that is ethically problematic if it ignores the widening divides brought about by lockdowns and shut-downs. The news media failed to make this connection. In some cases, though quoted sources were more careful to characterize the physiological effects of laughter (e.g., as when McGraw was quoted as saying the physical benefits of laughter are "mild"), news media were ethically irresponsible when implying that laughter offers protection against the virus. Finally, humor can be beneficial as a form of emotional coping, and there might be nothing ethically wrong with seeking a bit of distraction or escape during the monotony of stay-at-home orders. If, however, following Morreall (2009), people should be concerned about Coronavirus, that concern should include not just their own emotional reactions, but the broader implications of the pandemic, as well as the actions they should take to slow its spread (e.g., wearing a mask in public, practicing social distancing). Only one article was entirely devoted to how humor was being used to actually promote those actions. Takriti (2020) described a number of governmental initiatives. For example, the Vietnamese Ministry of Health created a music video "Jealous Coronavirus" to help prevent the infection's spread. Another example was a public service announcement (PSA) from Round Rock, Texas, reading: "Wash your hands like you just got done slicing jalapeños for a batch of nachos and you need to take your contacts out. That's like 20 s of scrubbing, y'all.” Ellis (2020) also mentioned the Vietnam example, and Goldberg (2020) described how New York governor Andrew Cuomo enlisted Danny DeVito to do a PSA promoting the importance of sheltering-inplace. Finally, Wellen's (2020) article included a number of thoughtful reflections 
from comedians about humor's role. However, these scattered examples, which could open up a societal debate about the role of humor in the public sphere during a pandemic, pale in comparison to the simpler message of humor helping isolated individuals cope with their emotions.

\section{Implications}

The findings of this study suggest several avenues for further investigation. Humor researchers should continue to explore how the news media represent humor. The non-representativeness of the sample used here is certainly a limitation. Future research is needed to examine the circulation of COVID-19 humor in non-Englishspeaking countries, as well as the extent of media coverage of that humor. Media have constructed a frame for understanding popular responses to pandemics (Gerlach 2016; Greenberg et al. 2019; Mitchell and Hamilton 2018), and now news media have articulated a frame for understanding humor as a response to global disease outbreaks, but only time will tell if this frame is utilized in the future. With the threat of viral-biological outbreaks, humor researchers should be prepared to explore how humor generated by ordinary citizens intersects with news media reporting on humor to shape public responses.

One of the main findings of this study was that news media framed the use of humor as an individual coping effort. This frame potentially reinforced the idea that people were helpless and powerless in the face of the pandemic. On the one hand, this is contrary to ideas about disaster humor that have been proposed by humor scholars: humor as a rebellion against media hegemony (Oring 1992); humor as an attempt to bring the event within the familiar sphere of popular culture (Kuipers 2005), humor as a way of dealing with existential anxiety (Smyth 1986). These ideas present people as active agents in responding to global events and the media coverage such events engender. On the other hand, emerging evidence suggests that exposure to social media during the early phases of the pandemic was associated with anxiety and depression (Bendau et al. 2020; Gao et al. 2020), as well as more misperceptions regarding COVID-19, and lower compliance with social distancing guidelines (Bridgman et al. 2020). Research is needed to explore the parameters within which immersing oneself in social media humor is effective and ineffective in both emotion- and problem-focused coping. We need to know if using humor to bring an event within the familiar sphere of popular culture, or alleviating existential anxiety, makes one more or less indifferent to the truthfulness of that event. Answers to such questions should then be disseminated to the news media so that they can provide more balanced coverage to the public. Then again, the news media frame was filled in by the quotes and examples of numerous 
comedians, scholars, and professionals, raising the penultimate question as to whether or not the pandemic narrative prepared us to believe, even for a little while, that the end had truly come.

Finally, we should continue to follow Morreall's (2009) lead, moving attention to humor ethics beyond the narrow issue of racist/sexist humor. The focus here was on the ethics of the news media's reporting on humor, but the principles could be used to examine COVID-19 humor itself. Prejudiced norm theory (Ford and Ferguson 2004), for example, could be expanded in this direction. In the present context, one could hypothesize that COVID-19 humor might release mistrustful feelings toward experts (e.g., scientists, public health officials), or arouse reactance against threatened freedoms, thereby influencing certain individuals not to engage in prevention actions. Once again, research on relationships between engaging humor and engaging in preventative actions could then inform the news media to help the public be more aware of connections between different domains.

\section{Conclusions}

News media reporting on the circulation of humor during the initial lockdown response to COVID-19 presented a remarkable opportunity to explore humor ethics. In the pandemic narrative (Gerlach 2016), people can only cope with the omnipresent threat of global viral outbreaks. Yet, what it means to cope and the consequences of coping behaviors are varied. All of us coping with the COVID-19 pandemic face the dilemma of Goldilocks (Briggs and Nichter 2009) when it comes to humor: how much humor is just the right amount? And, do different forms of humor weight the scales differently? And, how much do we want the news media to focus on humor? Humor ethics can help us find these balance points. In order to do so, however, it is necessary to articulate ethical principles and then apply those principles to particular cases. The intent of this investigation was to take a step in that direction.

\section{References}

Abril, Eulàlia P., Glen Szczypka \& Sherry L. Emery. 2017. LMFAO! Humor as a response to fear: Decomposing fear control within the extended parallel process model. Journal of Broadcasting \& Electronic Media 61. 126-143.

Aldwin, Carolyn M. 1994. Stress, coping, and development: An integrative perspective. New York, NY: Guilford Press. 
Al-Heeti, Abrar. 2020. Coronavirus memes help an isolated world cope with 'existential dread'. https://www.cnet.com/news/coronavirus-memes-are-helping-an-isolated-world-copewith-existential-dread/ (accessed 26 March 2020).

Amici, Patrizia. 2020. Humor in the age of COVID-19 lockdown: An explorative qualitative study. Psychiatria Danubina 32. S15-S20.

Aten, Jamie D. 2020. Delete that COVID-19 joke or forward it? https://www.psychologytoday.com/ us/blog/hope-resilience/202005/delete-covid-19-joke-or-forward-it (accessed 5 May 2020).

Beckerman, Jim. 2020. Can jokes help cope with a pandemic? Coronavirus spawns dark humor. Available at: https://www.northjersey.com/story/entertainment/columnists/jimbeckerman/2020/06/17/coping-with-coronavirus-pandemic-covid-19-spawns-dark-humor/ $5327568002 /$.

Benacka, Elizabeth. 2017. Rhetoric, humor, and the public sphere: From Socrates to Stephen Colbert. Lanham, MD: Lexington Books.

Benatar, David. 1999. Prejudice in jest: When racial and gender humor harms. Public Affairs Quarterly 13. 191-203.

Bendau, Anonia, Moritz Bruno Petzold, Lena Pyrkosch, Lea Mascarell Maricic, Felix Betzler, Janina Rogoll, Julie Große, Andreas Ströhle \& Jens Plag. 2020. Associations between COVID19 related media consumption and symptoms of anxiety, depression and COVID-19 related fear in the general population in Germany. European Archives of Psychiatry and Clinical Neuroscience. https://doi.org/10.1007/s00406-020-01171-6.

Bischetti, Luca, Paolo Canal \& Valentina Bambini. 2020. Funny but aversive: A large-scale survey of the emotional response to COVID-19 humor in the Italian population during the lockdown. Lingua 249. 102963.

Bridgman, Aengus, Eric Merkley, Peter John Loewen, Owen Taylor, Derek Ruths, Lisa Teichmann \& Oleg Zhilin. 2020. The causes and consequences of COVID-19 misperceptions: Understanding the role of news and social media. The Harvard Kennedy School of Misinformation Review 1. 1-18.

Briggs, Charles L. \& Mark Nichter. 2009. Biocommunicability and the biopolitics of pandemic threats. Medical Anthropology 28. 189-198.

Chattoo, Caty Borum \& Lauren Feldman. 2020. A comedian and an activist walk into a bar: The serious role of comedy in social justice. Oakland, CA: University of California Press.

Chew, Cynthia \& Gunther Eysenbach. 2010. Pandemics in the age of Twitter: Content analysis of tweets during the 2009 H1N1 outbreak. PloS One 5. e14118.

Christians, Clifford G. 2011. Journalism ethics in theory and practice. In George Chesney, Steve May \& Debashish Munshi (eds.), The handbook of communication ethics, 190-203. London: Routledge.

Christians, Clifford \& Kaarle Nordenstreng. 2004. Social responsibility worldwide. Journal of Mass Media Ethics 19. 3-28.

Davies, Christie. 2002. The mirth of nations. New Brunswick, NJ: Transaction Publishers.

Davies, Christie. 2003. Jokes that follow mass-mediated disasters in a global electronic age. In Narváez (ed.), Of corpse: Death and humor in folklore and popular culture, 15-34. Logan, UT: Utah State University Press.

Davis, Mark. 2017. “Is it going to be real?" Narrative and media on a pandemic. Forum: Qualitative Social Research 18.

De Sousa, Ronald. 1987. When is it wrong to laugh? In John Morreall (ed.), The philosophy of laughter and humor, 226-249. Albany, NY: State University of New York Press. 
Edwards, Kim R. \& Rod A. Martin. 2010. Humor creation ability and mental health: Are funny people more psychologically healthy? Europe's Journal of Psychology 6. 196-212.

Ellis, Emma Gray. 2020. Is it OK to make coronavirus memes and jokes? https://www.wired.com/ story/coronavirus-memes-humor/ (accessed 5 March 2020).

Erskine, Chris. 2020. The coronavirus pandemic is terrifying - it's OK to laugh. https://www. latimes.com/california/story/2020-04-30/coronavirus-jokes-videos-memes-can-help-usget-through-this (accessed 30 April 2020).

Ford, Thomas E. \& Mark A. Ferguson. 2004. Social consequences of disparagement humor: A prejudiced norm theory. Personality and Social Psychology Review 8. 79-94.

Ford, Thomas E., Kyle Richardson \& Whitney E. Petit. 2015. Disparagement humor and prejudice: Contemporary theory and research. Humor 28. 171-186.

Ford, Thomas E., Shaun K. Lappi \& Christopher J. Holden. 2016. Personality, humor styles and happiness: Happy people have positive humor styles. Europe's Journal of Psychology 12. 320-337.

Fraser, Heather. 2004. Doing narrative research: Analysing personal stories line by line. Qualitative Social Work 3. 179-201.

Gajanan, Mahita. 2020. Prince William jokes about 'spreading coronavirus' at royal engagement in Dublin. https://time.com/5795398/prince-william-dublin-guinnness-coronavirus/ (accessed 4 March 2020).

Gao, Junling, Pinpin Zheng, Yingnan Jia, Hao Chen, Yimeng Mao, Suhong Chen, Yi Wang, Hua Fu \& Junming Dai. 2020. Mental health problems and social media exposure during COVID-19 outbreak. PloS One 15. e0231924.

Gerlach, Neil Allen. 2016. From outbreak to pandemic narrative: Reading newspaper coverage of the 2014 Ebola epidemic. Canadian Journal of Communication 41. 611-630.

Goldberg, Barbara. 2020. 'Humor is healing': Laughing soothes nerves during COVID-19 trauma. https://www.reuters.com/article/us-health-coronavirus-usa-humor/humor-is-healinglaughter-soothes-nerves-during-covid-19-trauma-idUSKBN21B33Y (accessed 24 March 2020).

Gordon, Sherri. 2020. How humor can ease the stress of COVID-19. https://www.verywellmind. com/it-s-ok-to-laugh-even-during-a-pandemic-4843082 (accessed 11 May 2020).

Gozzi, Nicolò, Michele Tizzani, Michele Starnini, Fabio Ciulla, Daniela Paolotti, André Panisson \& Perra Nicola. 2020. Collective response to media coverage of the COVID-19 pandemic on Reddit and Wikipedia: Mixed-methods analysis. Journal of Medical Internet Research 22. e21597.

Greenberg, Josh, Gabriela Capurro, Eve Dubé \& S. Michelle Driedger. 2019. Measles, Mickey, and the media: Anti-vaxxers and health risk narratives during the 2015 Disneyland outbreak. Canadian Journal of Communication 44. 175-189.

Greengross, Gil. 2020. Is it okay to laugh during a pandemic? https://theconversation.com/is-itokay-to-laugh-during-a-pandemic-136755 (accessed 5 May 2020).

Hileman, Ami. 2020. Delete that COVID-19 joke or forward it? Understanding how different types of humor impact our resilience in a pandemic. https://www.psychologytoday.com/us/blog/ hope-resilience/202005/delete-covid-19-joke-or-forward-it (accessed 1 May 2020).

Holshue, Michelle L., Chas DeBolt, Lindquist Scott, Kathy H. Lofy, John Wiesman, Hollianne Bruce, Christopher Spitters, Keith Ericson, Sara Wilkerson, Ahmet Tural, Diaz George, Amanda Cohn, LeAnne Fox, Anita Patel, Susan I. Gerber, Lindsay Kim, Suxiang Tong, Xiaoyan Lu, Steve Lindstrom, Mark A.Pallansch, William C. Weldon, Holly M. Biggs, Timothy M. Uyeki \& Satish K. Pillai. 2020. First case of 2019 novel coronavirus in the United States. The New England Journal of Medicine 382. 929-936. 
Hu, Yang. 2020. Intersecting ethnic and native-migrant inequalities in the economic impact of the COVID-19 pandemic in the UK. Research in Social Stratification and Mobility 68. 100528.

Jaeger, Mads Meier \& Ea Hoppe Blaabaek. 2020. Inequality in learning opportunities during COVID-19: Evidence from library takeout. Research in Social Stratification and Mobility 68. 100524.

Jensen, Erin. 2020. Is it OK to laugh at coronavirus jokes and memes? https://www.usatoday.com/ story/life/2020/04/03/coronavirus-memes-and-jokes-ok-to-laugh/5116078002/ (accessed 10 April 2020).

Katz, Jennifer \& Dimitri Wing-Paul. 2020. Taking a joke seriously: When does humor affect responses to the slurring of people with intellectual disabilities? Humor 33. 563-579.

Kole, William J. 2020. If you don't laugh, you cry: Coping with coronavirus through humor. https:// www.denverpost.com/2020/03/26/coping-with-coronavirus-through-humor/ (accessed 26 March 2020).

Krawczyk, K., T. Chelkowski, S. Mishra, D. Xifara, B. Gibert, D. J. Laydon, S. Flaxman, T. Mellan, V. Schwämmle, R. Röttger, J. T. Hadsund \& S. Bhatt. 2020. Quantifying the online news media coverage of the COVID-19 pandemic. https://doi.org/10.1101/2020.12.24.20248813 (Epub ahead of print).

Kristal, Tali \& Meir Yaish. 2020. Does the coronavirus pandemic level the gender inequality curve? (It doesn't). Research in Social Stratification and Mobility 68. 100520.

Kuipers, Giselinde. 2005. “Where was King Kong when we needed him?” Public discourse, digital disaster jokes, and the functions of laughter after 9/11. The Journal of American Culture 28. 70-84.

Kuipers, Giselinde. 2006. Good humor, bad taste: A sociology of the joke. Berlin: Mouton de Gruyter.

Kupferschmidt, Kai \& Jon Cohen. 2020. Will novel virus go pandemic or be contained? Science 367. 610-611.

Laws, Joseph. 2020. 'We're meant to die from climate change!' Grumpy Greta Thunberg meme goes viral as social media users tackle coronavirus with dark humor. https://www.dailymail.co. uk/news/article-8118459/Social-media-flooded-memes-dark-humour-amid-coronaviruspanic.html (accessed 17 March 2020).

Lazarus, Richard S. \& Susan Folkman. 1984. Stress, appraisal, and coping. New York: Spring Publishing Company.

Leazenby, Lauren. 2020. The 'meme generation' creates humor to cope with coronavirus. https:// columbiachronicle.com/the-meme-generation-creates-humor-to-cope-with-coronavirus (accessed 23 April 2020).

Lemish, Dafna \& Nelly Elias. 2020. “We decided we don’t want children. We will let them know tonight": Parental humor on social media in a time of coronavirus pandemic. International Journal of Communication 14. 5261-5287.

Malone, Michael R. 2020. It's no jokes, humor goes viral in the time of coronavirus. https://news. miami.edu/stories/2020/04/its-no-joke,-humor-goes-viral-in-the-time-of-coronavirus.html (accessed 20 April 2020).

Martin, Rod A. 2001. Humor, laughter, and physical health: Methodological issues and research findings. Psychological Bulletin 127. 504-519.

Martin, Rod A. 2008. Humor and health. In Victor Raskin (ed.), The primer of humor research, 479-521. Berlin: Mouton de Gruyter.

McGhee, Paul. 2010. Humor: The lighter path to resilience and health. Bloomington: AuthorHouse. 
McTague, Tom. 2020. Yes, make coronavirus jokes. https://www.theatlantic.com/international/ archive/2020/04/humor-laughter-coronavirus-covid19/609184/ (accessed 3 April 2020).

Mitchell, Scott \& Sheryl N. Hamilton. 2018. Playing at apocalypse: Reading Plague Inc. in pandemic culture. Convergence: The International Journal of Research into New Media Technologies 24. 587-606.

Møller, Mette. 2020. What's funny about coronavirus? The Internet abounds with corona jokes. But why are we laughing at something gravely serious? https://sciencenordic.com/denmarkepidemic-humour/whats-funny-about-coronavirus/1689916 (accessed 5 June 2020).

Morreall, John. 2009. Comic relief: A comprehensive philosophy of humor. Chichester: WileyBlackwell.

Mulkay, Michael. 1988. On humor: Its nature and its place in modern society. Cambridge: Basil Blackwell Inc.

Neben, Tillman. 2015. A model of defensive information avoidance in information systems use. In Thirty sixth international conference on information systems.

Oring, Elliott. 1992. Jokes and their relations. Lexington, KY: The University Press of Kentucky.

Oring, Elliott. 2003. Engaging humor. Urbana, IL: University of Illinois Press.

Papousek, Ilona. 2018. Humor and well-being: A little less is quite enough. Humor 31. 311-327.

Peifer, Jason T. 2012. Can we be funny? The social responsibility of political humor. Journal of Mass Media Ethics 27. 263-276.

Pew Research Center. 2020. Americans' views of the news media during the COVD-19 outbreak.

Qian, Yue \& Wen Fan. 2020. Who loses income during the COVID-19 outbreak? Evidence from China. Research in Social Stratification and Mobility 68. 100522.

Raskin, Victor. 1985. Semantic mechanisms of humor. Dordrecht, Holland: D. Reidel Publishing Company.

Recchi, Ettore, Emanuele Ferragina, Emily Helmeid, Stefan Pauly, Mirna Safi, Nicolas Sauger \& Schradie Jen. 2020. The "eye of the hurricane" paradox: An unexpected and unequal rise of well-being during the COVID-19 lockdown in France. Research in Social Stratification and Mobility 68. 100508.

Reissman, Catherine Kohler. 1993. Narrative analysis. Newbury Park, CA: Sage.

Ruch, Willibald, Jennifer Hofmann, Tracey Platt \& René Proyer. 2014. The state-of-the-art in gelotophobia research: A review and some theoretical extensions. Humor 27. 23-45.

Schucht, Eric. 2020. Comedians find humor amid coronavirus pandemic. Available at: https:// www.jewishexponent.com/2020/06/03/comedians-find-humor-amid-coronaviruspandemic/.

Smuts, Aaron. 2010. The ethics of humor: Can your sense of humor be wrong? Ethical Theory and Moral Practice 13. 333-347.

Smyth, Willie. 1986. Challenger jokes and the humor of disaster. Western Folklore 45. 243-260.

Takriti, Danna. 2020. Silly songs, dances, and skits: The world is using humor to curb coronavirus's spread. https://www.vox.com/2020/3/6/21167987/world-humor-curbcoronavirus-spread-washington-singapore-vietnam (accessed 6 March 2020).

Taylor, Shelley E. \& Annette L. Stanton. 2007. Coping resources, coping processes, and mental health. Annual Review of Clinical Psychology 3. 377-401.

Titze, Michael. 2009. Gelotophobia: The fear of being laughed at. Humor 22. 27-48.

Wald, Priscilla. 2008. Contagious: Cultures, carriers, and the outbreak narrative. Durham, NC: Duke University Press. 
Wasserman, Herman. 2020. Laughter in the time of a pandemic: Why South Africans are joking about coronavirus. https://theconversation.com/laughter-in-the-time-of-a-pandemic-whysouth-africans-are-joking-about-coronavirus-133528 (accessed 15 March 2020).

Wellen, Brianna. 2020. Jokes in the time of coronavirus: How soon is "too soon" when you're living through it? https://www.chicagoreader.com/chicago/covid-19-jokes/Content? oid=78640318 (accessed 19 March 2020).

Wikipedia. 2020. U.S. state and local government responses to the COVID-19 pandemic. Available at: https://en.wikipedia.org/wiki/U.S._state_and_local_government_responses_to_the_ COVID-19_pandemic.

Williams, Alex. 2020. It's OK to find humor in some of this. https://www.nytimes.com/2020/04/ 22/style/coronavirus-humor.html (accessed 22 April 2020).

Williams, Brue A. \& Michael X. Delli Carpini. 2009. The eroding boundaries between news and entertainment and what they mean for democratic politics. In Lee Wilkins \&

Clifford G. Christians (eds.), The handbook of mass media ethics, 177-188. New York: Routledge.

\section{Bionote}

\section{Nathan Miczo}

Western Illinois University, Macomb, USA

n-miczo@wiu.edu

Nathan Miczo is a Professor of Communication in the Department of Communication at Western Illinois University. He received his B.A. in Broadcasting from Arizona State University, and both his M.A. and Ph.D. in Communication from the University of Arizona. His primary areas of interest in humor are humor production, humor theory, and humor in interpersonal communication. 